\title{
Impact of uteroplacental insufficiency on postnatal rat male gonad
}

\author{
Valentina Pampanini1, Daniela Germani2, Antonella Puglianiello², \\ Jan-Bernd Stukenborg', Ahmed Reda', Iuliia Savchuk', Kristín Rós Kjartansdóttir1, \\ Stefano Cianfarani1,3 and Olle Söder ${ }^{1}$ \\ 1Department of Women's and Children's Health, Pediatric Endocrinology Unit, Q2:08, Karolinska Institutet and \\ University Hospital, Stockholm, Sweden \\ 2Department of Systems Medicine, Tor Vergata University, Rome, Italy \\ 3Dipartimento Pediatrico Universitario Ospedaliero 'Bambino Gesù' Children's Hospital - Tor Vergata University, \\ Rome, Italy
}

Correspondence should be addressed to V Pampanini Email

valentina.pampanini@ki.se

\begin{abstract}
Prenatal events such as intrauterine growth restriction can affect gonadal development of the offspring and have an impact on reproductive health. To investigate the effects of intrauterine growth restriction induced by uterine artery ligation on the postnatal rat testis. Pregnant rats underwent uterine artery ligation at day 19 of gestation. Offspring were killed at 5, 20 and 40 days post-partum (dpp). At killing, one gonad was snapfrozen in liquid nitrogen and processed for RNA and steroid extraction. The other gonad was formalin-fixed for histology. Gene expression was analyzed by TaqMan Low-Density Array. Intratesticular testosterone, estradiol and serum gonadotrophins were measured. Thirty genes were dysregulated in intrauterine growth-restricted rats compared to controls, among which markers of Sertoli cell and Leydig cell function, cell metabolism and growth factors. Testis weights were significantly reduced at 5 and $20 \mathrm{dpp}$ in intrauterine growth-restricted rats and caught-up by $40 \mathrm{dpp}$. Accordingly, Sertoli cell number was significantly lower in 5 dpp intrauterine growth-restricted rats. At $20 \mathrm{dpp}$, intratesticular testosterone was significantly increased in intrauterine growth-restricted rats, whereas serum gonadotrophins were unchanged. IUGR altered the gene expression in the rat testes up to peripubertal age and reduced testis size and Sertoli cell number in neonatal age. Multiple mechanisms encompassing genetic changes and steroid production by the testis may be involved in the catch-up growth phase that restored testis size by $40 \mathrm{dpp}$. Permanent consequences on organ function and gamete integrity cannot be excluded and deserve further investigations.
\end{abstract}
Key Words
- intrauterine growth restriction
- developmental origins of health and disease
- uteroplacental insufficiency
- testis

\section{Introduction}

Adverse conditions during fetal life, such as low nutrient and/or oxygen supply from the placenta, can lead to intrauterine growth restriction (IUGR) and low birth weight. Besides affecting body growth, a suboptimal intrauterine environment can influence the expression of fetal genes and has an impact on growth and development of multiple organs and long-term health. This principle, pioneered by David Barker and coworkers in the early 90s, has later been termed 'Developmental Origins of Health and Disease' (DOHaD) hypothesis and is nowadays supported by broad scientific evidence (Barker 1990, Hales \& Barker 2001, Silveira et al. 2007). 
Intrauterine stress produces fetal gene reprogramming generating oxidative stress and the production of reactive oxygen species (ROS). Those molecules can directly bind to specific sites on DNA and cause genetic and epigenetic modifications, e.g. by interfering with DNA methylation and histone configuration (Thompson \& Al-Hasan 2012).

IUGR and low birth weight are associated with an increased risk of cardiovascular and metabolic diseases in adult life (Barker etal. 1990, 1993, Hales etal. 1991, Law etal. 1992, Barker 1995, Forsen et al. 1999, Arends et al. 2005). As indicated by experimental IUGR models, permanent modification in the genetic programming can account for this association. Fetal growth restriction dysregulates key enzymes involved in metabolic processes, especially those related to glucose metabolism (e.g. phosphoenolpyruvate carboxykinase (Pepck), glucose transporter 1 and 4 (Glut-1 and Glut-4)), and these changes have been identified in multiple organs, such as skeletal muscle, liver and heart (Tsirka et al. 2001, Peterside et al. 2003, Selak et al. 2003, Vuguin et al. 2004).

In addition to the well-known association between low birth weight and cardiometabolic diseases, IUGR has been related to an increased risk of male reproductive health disorders, such as cryptorchidism, hypospadias and testicular cancer, grouped under the definition of testicular dysgenesis syndrome (TDS) (Skakkebaek et al. 2001, Main et al. 2006). Previous studies reported alterations of puberty and hormonal levels in boys, but the results are conflicting and difficult to compare due to different inclusion criteria and definitions used (Persson et al. 1999, Hokken-Koelega 2002, Veening et al. 2004, Jensen et al. 2007, Hernandez \& Mericq 2008, Dupont et al. 2012, Zambrano et al. 2014).

In rats and sheep, gonadal morphology, functionality and sperm parameters are altered by modifications of the intrauterine environment during critical windows of fetal development, but most of these experimental studies have used maternal nutrition manipulation to produce IUGR animals (Engelbregt et al. 2000, 2002, Rae et al. 2002, Zambrano et al. 2005, Kotsampasi et al. 2009, Genovese et al. 2010, Toledo et al. 2011).

In Western industrialized countries, uteroplacental insufficiency (UPI) is the most common cause of IUGR (Gagnon 2003). Therefore, animal models using surgically induced UPI are more relevant to pregnancies in developed countries than manipulation of maternal diet (Vuguin 2007).

To our knowledge, only two studies have investigated the effects of IUGR induced by UPI on the testis. UPI coupled with postnatal undernutrition delayed the onset of puberty and altered testicular function by a reduction of testosterone levels (Engelbregt et al. 2000, 2002).

Here, we used a model of UPI initiated at day 19 of gestation in pregnant rats, to investigate the effect of IUGR on the gene expression, structure and function in the postnatal testis.

\section{Material and methods}

\section{Animals}

All protocols for the study were approved by the Committee for Animal Research of Tor Vergata University, Rome, Italy. Animal experiments were performed according to the Guide for the Care and Use of Laboratory Animals of the National Institutes of Health (NIH Publication No. 85-23, revised 1996). All procedures complied with Italian regulations for laboratory animal care, according to the guidelines and under supervision of the Animal Technology Station, Interdepartmental Service Center, Tor Vergata University, Rome, Italy.

The animal model was developed as previously described (Puglianiello et al. 2007). Time-dated SpragueDawley pregnant rats (Charles River Laboratories Inc.) were delivered to our animal facilities at least three days prior to the first surgery (day 15-16 after conception). The supplier checked the vaginal plug to confirm mating and defined day one of pregnancy as the day immediately following the night where the animals mated. After arrival at our facility, animals were allowed standard chow diet and water ad libitum and maintained on a $12 \mathrm{~h}$ light/darkness cycle at $21^{\circ} \mathrm{C}$. IUGR was induced by bilateral ligation of the uterine arteries on day 19 of gestation according to a modification of the method of Wigglesworth (1964). Animals were anesthetized with intramuscular injections of xylazine $(10 \mathrm{mg} / \mathrm{kg}$ ) and ketamine $(50 \mathrm{mg} / \mathrm{kg}$ ) (SigmaAldrich), a four to five $\mathrm{cm}$ long lower midline abdominal incision was made and the uterine arteries of both sides were localized and ligated. Suture was placed around both the uterine arteries and then either tied or withdrawn before closing the abdomen. The latter protocol (sham procedure) was used to generate control animals, aiming at the limitation of confounding factors, such as anesthesia and surgical stress. The surgical procedure lasted 10-15 min, and animals recovered within threefour hours from the administration of anesthetic drugs. Dams were returned to the animal facilities and housed in individual cages. Dams delivered spontaneously during the night between day 22 and 23. Pups were weighed in the morning of day 23. Significant IUGR was considered

Published by Bioscientifica Ltd. 
as a birth weight $<-2$ SDS compared to the mean birth weight of the control litter. After birth, dams were killed and pups were assigned to feeding dams. To standardize postnatal conditions (i.e. to ensure an equal access to lactation) litter sizes were reduced to six offspring. Pup weights were recorded on day 0 and subsequently once a week until the end of experiments. At 21 days postpartum (d $p p$ ), pups were weaned onto standard rat chow diet (Mucedola S.R.L., Milano, Italy), separated from dams and placed in groups of three to five, with the males and females separated. For the purpose of this study, only male pups were selected. Animals were killed through cervical dislocation at postnatal day 5, 20 and $40 \mathrm{~d} p p$. To limit confounding factors and to ensure biological variability of the observed phenotype, each group of IUGR and shams at 20 and $40 \mathrm{~d} p p$ included six animals from at least three different litters. For the $5 \mathrm{~d} p p$ old animals, comparisons were made between seven IUGR and four shams, respecting the same principle of litter variability.

\section{Testicular histology and immunohistochemistry}

At killing, testes were immediately excised from killed animals, trimmed of fat and connective tissue and weighed. For histological purpose, one gonad was fixed in 4\% paraformaldehyde (PFA; P/N15812-7, Sigma-Aldrich) overnight at $4^{\circ} \mathrm{C}$, followed by serial dehydration in 30,50 , 70 and $80 \%$ aqueous ethanol for $24 \mathrm{~h}$ at each concentration, at room temperature (RT). Afterward, samples were placed for six hours in 96\% ethanol, and then in 99.6\% ethanol and $100 \%$ butyl acetate (P/N 45860, SigmaAldrich), each overnight at RT and finally embedded in paraffin (Paraplast X-TRA; P/N P3808, Sigma-Aldrich) at $61^{\circ} \mathrm{C}$ overnight. Paraffin-embedded tissue was cut to a thickness of five micrometer, using a Biocut sectioning machine (Reichert-Jung, NY, USA), mounted on microscope slides (P/N10143352, Superfrost Plus, Thermo Scientific) and placed at $37^{\circ} \mathrm{C}$ overnight. Tissue sections were dewaxed with xylene (P/N 02080, HistoLab, Gothenburg, Sweden) for $10 \mathrm{~min}$ and then serially rehydrated with 99.6, 96 and 70\% aqueous ethanol, each step being performed twice for five minutes.

For histological evaluations, samples were subsequently stained with periodic acid-Schiff (PAS) kit (P/N 395B-1KT, Sigma-Aldrich). In brief, after washing twice with distilled water, samples were incubated for five minutes with periodic acid and then rinsed with tap water followed by distilled water for two times. Samples were then incubated for $15 \mathrm{~min}$ with Schiff's reagent and washed again as previously described. Slides were finally incubated with hematoxylin solution modified according to Gill III for two min, washed with tap water for three minutes, dehydrated with increasing aqueous ethanol solutions and $100 \%$ xylene and finally mounted with Entellan new (P/N 1079610100, Merck) and cover glass.

After dewaxing in xylene and partial rehydration in two $100 \%$ ethanol baths, samples for immunohistochemical (IHC) staining were incubated with $3 \% \mathrm{H}_{2} \mathrm{O}_{2}$ in $96 \%$ ethanol for $10 \mathrm{~min}$ at RT for endogenous peroxidase blocking. Afterwards, tissue sections were subjected to antigen retrieval using citrate buffer $(\mathrm{pH} 6.0)$ at $95^{\circ} \mathrm{C}$ for $30 \mathrm{~min}$, cooled down for $20 \mathrm{~min}$ and then incubated with $10 \%$ goat serum in phosphate-buffered saline (PBS) plus $1 \%$ bovine serum albumin (BSA) for $30 \mathrm{~min}$ at RT. Slides were subsequently incubated with primary antibody against Wilms tumor-1 (WT1) (P/N ab89901, Abcam) or unspecific IgGs (for negative control) dissolved in $10 \%$ goat serum, $1 \% \mathrm{BSA}-1 \times \mathrm{PBS}$, overnight at $4^{\circ} \mathrm{C}$. After washing three times for five minutes each with $1 \times$ Trisbuffered saline (TBS) plus 0.01\% Tween20 (P/N P1379, Sigma-Aldrich), slides were incubated with biotinylated secondary antibody $(\mathrm{P} / \mathrm{N}$ ab64256, Abcam), and then with avidin-biotin-peroxidase complex prepared using Vectastain ABC kit (P/N PK-6100, Vector Laboratories, Burlingame, CA, USA) for $30 \mathrm{~min}$ at $37^{\circ} \mathrm{C}$. After washing again three times, slides were stained with $\mathrm{DAB}(\mathrm{P} / \mathrm{N}$ SK-4105, Vector Laboratories) for 30-60s at RT, washed twice for five min in $\mathrm{H}_{2} \mathrm{O}$, counter-stained with Hämalaun solution (1.09249.1000, Merck), rinsed for five min with running tap water, dehydrated with gradually increasing concentrations of ethanol, cleared with xylene and mounted with cover glass.

\section{RNA isolation and CDNA synthesis}

Total RNA was extracted from whole frozen testes and stored at $-80^{\circ} \mathrm{C}$ using an RNeasy Mini Kit (P/N 74104, Qiagen). In brief, samples were dissolved in Qiagen lysis buffer and then homogenized twice for $30 \mathrm{~s}$ in an ULTRATURRAX T25 homogenizer (JANKE and KUNKEL, Staufen, Germany). Subsequently, the supernatant was mixed with 0.5 times its volume of $70 \%$ ethanol. The mixture was then transferred to RNeasy spin columns and processed according to the manufacturer protocol.

RNA concentrations were quantified using a singlebeam UV/vis spectrophotometer (P/N 6132000032, Eppendorf, Hamburg, Germany). To generate cDNA, one microgram of total RNA was reverse-transcribed on http://joe.endocrinology-journals.org

DOI: $10.1530 / J O E-16-0418$
(C) 2017 The authors Printed in Great Britain
Published by Bioscientifica Ltd 
a thermocycler (P/N 4359659, Applied Biosystems) using random hexamers in a total reaction volume of $20 \mu \mathrm{L}$. The IScript cDNA synthesis kit (P/N 170-8891, Bio-Rad) was used as instructed by the manufacturer.

\section{TaqMan low-density arrays (TLDAs)}

TLDA cards (P/N 4342259, ABI, Hilden, Germany) were used for comparative analysis of gene expression of IUGR and control animals, according to the manufacturer's protocol. Briefly, the TLDA cards are based on TaqMan chemistry where gene expression of a panel of 96 genes is analyzed in one run. The TLDA cards were pre-loaded with 96 TaqMan gene expression assays of importance for proliferation, apoptosis, cellular energy, germ cell (GC) and somatic cell function and differentiation, and six endogenous controls were assigned for normalization. Gene expression was normalized to the mean of five out of six endogenous controls (Actin beta, Beta-2-microglobulin, Catenin beta 1, Eukaryotic translation elongation factor 1 alpha 1 and Glyceraldehyde-3-phosphate dehydrogenase) of the same sample $\left(\mathrm{dC}_{\mathrm{T}}\right)$, selected according to their stability. Data from one randomly chosen animal were used as a calibrator $\left(\mathrm{dd}_{\mathrm{T}}\right)$ and data from all other animals were normalized to it. Gene expression was finally presented as relative expression (using the fold change (2-ddCT) method for calculation).

TaqMan gene expression Master Mix (P/N 4369510, Applied Biosystems) was used when running the TLDA assays.

\section{Intratesticular steroids measurement}

Intratesticular testosterone and estradiol were assessed as a measure of Leydig cells (LC) and Sertoli cell (SC) enzymatic activity in 20 and $40 \mathrm{~d} p p$ animals. Steroids were extracted from samples stored at $-80^{\circ} \mathrm{C}$ by adding $0.5 \mathrm{~mL}$ ethyl acetate (P/N 1096232500, Merck), followed by vigorous automated shaking for $15 \mathrm{~min}$. After centrifugation for two min at $16,000 \boldsymbol{g}$, the resulting supernatant was separated and the residue was re-subjected to the same procedure. The two ethyl acetate extracts were combined and evaporated overnight; the pellet obtained was dissolved in PBS. The COAT-A-COUNT RIA kit (P/N TKTT2, Siemens) and DRG Estradiol ELISA (P/N EIA-2693, DRG International, Inc., Springfield Township, NJ, USA) were used to quantify testosterone and estradiol, respectively, with intra-assay variability CV of less than $5 \%$ and interassay variability $\mathrm{CV}$ of less than $10 \%$ for both, according to the manufacturer's protocol. Each sample was analyzed in duplicate, and values were extrapolated from a standard curve prepared with known concentrations of testosterone and estradiol provided with the kits.

\section{Serum gonadotropins measurement}

Luteinizing hormone (LH) and follicle-stimulating hormone (FSH) serum levels were measured in 20 and 40 $\mathrm{d} p p$ animals by ELISA kit (P/N CEA441Ra and CEA830Ra, respectively; USCN Life Science, Inc. Houston, TX, USA), with intra-assay variability CV of less than $10 \%$ and inter-assay variability CV of less than $12 \%$ for both in accordance with manufacturer's protocol.

\section{Statistical analysis}

To detect a difference in average $z$-scores between the control and treated of 0.5 with $90 \%$ power at the 5\% significance level, six animals per group were included in the study, except for the $5 \mathrm{~d} p p$ group that was composed by 7 IUGR and 4 sham animals. Data were expressed as mean \pm S.D. Statistical analyses were performed using Student's $t$-test to compare the IUGR group with the controls. Differences were considered statistically significant at $P \leq 0.05$.

\section{Results}

\section{IUGR-affected network of selected genes}

We analyzed the relative quantitation of gene expression of 90 different markers of specific cellular functions in the rat testis at 5, 20 and $40 \mathrm{~d} p p$ (Supplementary Table 1, see section on supplementary data given at the end of this article) by TaqMan Low-Density Array (TLDA). A total of 30 genes were differentially expressed in the testes of IUGR vs sham rats (Supplementary Table 2). Among those, 19 genes showed significantly higher expression and 11 genes showed significantly lower expression in IUGR than in sham animals (Fig. 1).

Genes involved in the regulation of cellular energetic homeostasis were modulated in IUGR animals. Expression of citrate synthase (Cs) and hydroxyacyl-CoA dehydrogenase (Hadh) was upregulated in IUGR rats at 5 $\mathrm{d} p p$, compared to controls $(P<0.02)$, whereas at $40 \mathrm{~d} p p$, lactate dehydrogenase- $\mathrm{a},-\mathrm{b}$ and $-\mathrm{c}(L d h-a, L d h-b$ and $L d h-c)$ were downregulated $(P<0.002, P<0.02, P<0.02$, respectively) and solute carrier family 2 member 1

Published by Bioscientifica Ltd 
A

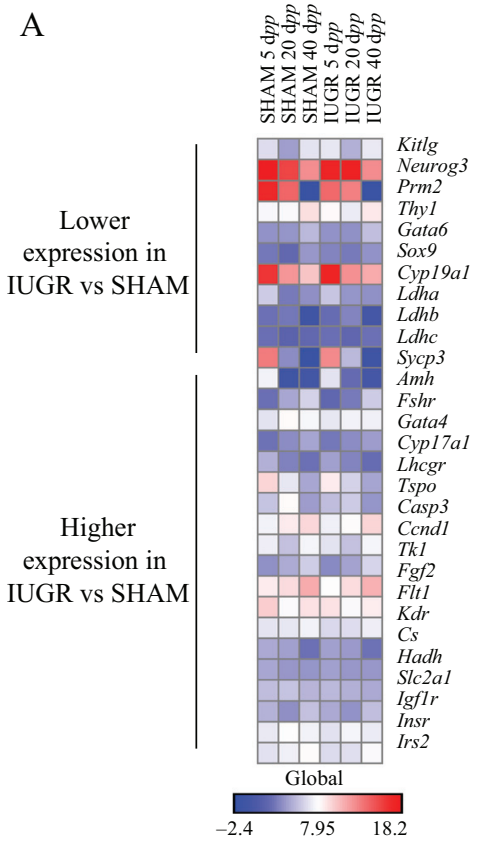

B

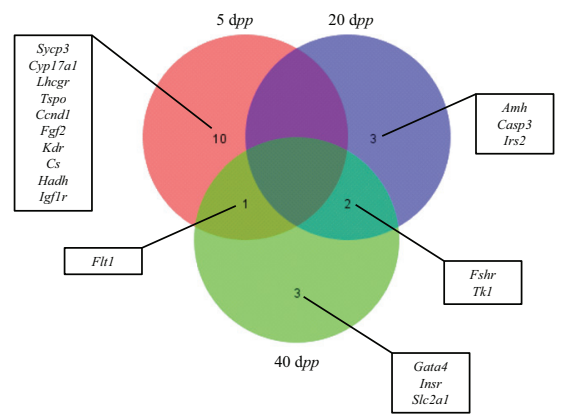

$\mathrm{C}$

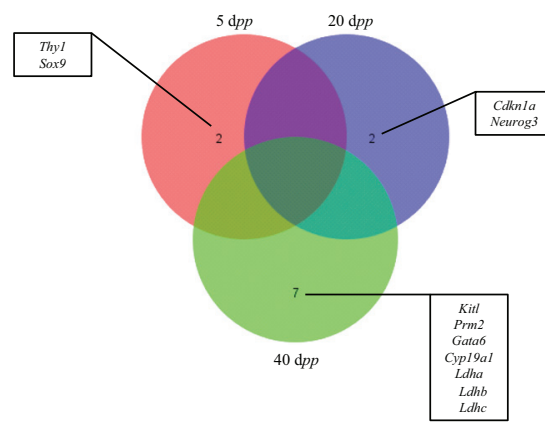

\section{Figure 1}

TaqMan Low-Density Array analysis of gene expression in IUGR and sham animals at 5, 20 and $40 \mathrm{dpp}$. (A) Significantly lower and higher expression $(P<0.05)$ of genes in IUGR animals relative to sham ones. (B) Specific differences in gene expression between animal groups, with higher expression in IUGR vs sham animals, and (C) lower expression in IUGR vs sham animals. For gene abbreviations and corresponding names see Supplementary Table 1.
(Slc2a1) was upregulated $(P<0.01)$ in IUGR rats compared to controls.

Three genes controlling cell proliferation, cyclin D1 $(C c d n 1)$, cyclin-dependent kinase inhibitor 1A (Cdkn1a) and thymidine kinase 1 (Tk1) showed a significant congruent variation at the three age points $(5,20$ and 40 $\mathrm{d} p p$, respectively).

Several genes marking SC and LC function were affected by IUGR. Expression of the SC marker SRY (sex-determining region Y)-box 9 (Sox9) was decreased in IUGR rats at $5 \mathrm{~d} p p$, compared to shams $(P<0.02)$. At 20 and $40 \mathrm{~d} p p$, follicle-stimulating hormone receptor (Fshr) was significantly upregulated in IUGR rats $(P<0.05$ and $P<0.02$, respectively), whereas Kit ligand (Kitl) was downregulated in IUGR rats $40 \mathrm{~d} p p$, compared to shams $(P<0.02)$.

Moreover, at $5 \mathrm{~d} p p$, two genes involved in steroidogenic pathways for androgen synthesis in LC, cytochrome P450 family 17 (Cyp17) and translocator protein (Tspo), were both upregulated in IUGR rats $(P<0.05$ and $P<0.04$, respectively). At $20 \mathrm{~d} p p$, no variations were detected, whereas at $40 \mathrm{~d} p p$, cytochrome P450 family 19 (Cyp19) expression was downregulated in IUGR rats $(P<0.01)$.

Given the known role of insulin and insulin-like growth factors (IGFs) in the regulation of somatic cells development and function within the testis, testosterone production and spermatogenesis itself (Gnessi et al. 1997, Sofikitis et al. 2008, Pitetti et al. 2013), we investigated the expression of $I g f 1$, Igf1 receptor (Igf1r), Igf-binding protein 3 (Igfbp3), insulin (Ins), Ins receptor (Insr) and insulin receptor substrate 2 (Irs2). At $5 \mathrm{~d} p p$, we found an increased expression of $I g f 1 r$ in IUGR rats compared to controls $(P=0.05)$. Irs 2 expression was also upregulated in $20 \mathrm{~d} p p$ IUGR rats $(P<0.05)$ as well as the expression of Insr at $40 \mathrm{~d} p p(P<0.05)$.

\section{Testis size}

Testes from IUGR rats were significantly reduced in weight at $5 \mathrm{~d} p p$ compared to sham rats $(5.9 \pm 1.2$ vs $10.8 \pm 1.9 \mathrm{mg}, P<0.001$ ) (Fig. $2 \mathrm{~A}$ ) as well as the mean body weight $(9.6 \pm 1.9$ vs $13.2 \pm 0.6 \mathrm{~g}, P<0.05)$ (Fig. $2 \mathrm{~B})$. The mean of both testes weight and body weight of IUGR rats caught-up from $20 \mathrm{~d} p p$ (Fig. 2A and B).

When testes weight was normalized to body weight, the ratio of testes weights to body weight was significantly reduced at $5 \mathrm{~d} p p$ and $20 \mathrm{~d} p p$ in IUGR compared to sham rats $(P<0.05)$. At $40 \mathrm{~d} p p$, the difference was no longer significant although a tendency to reduction remained in IUGR rats compared to shams (Fig. 2C).

\section{Testis histology}

Histological examination of testicular cross-sections at 5, 20 and $40 \mathrm{~d} p p$ by PAS staining revealed no change of the morphology between IUGR and sham animals (Supplementary Fig. 1).
(C) 2017 The authors Printed in Great Britain
Published by Bioscientifica Ltd 
A
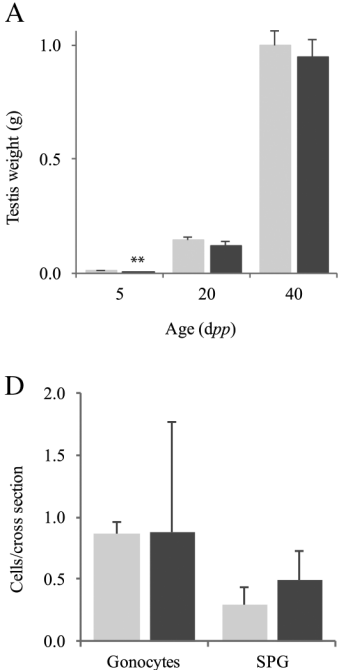

G

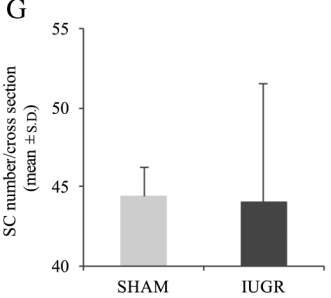

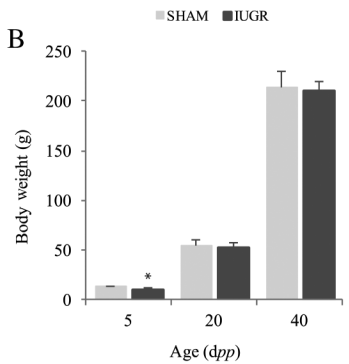

E
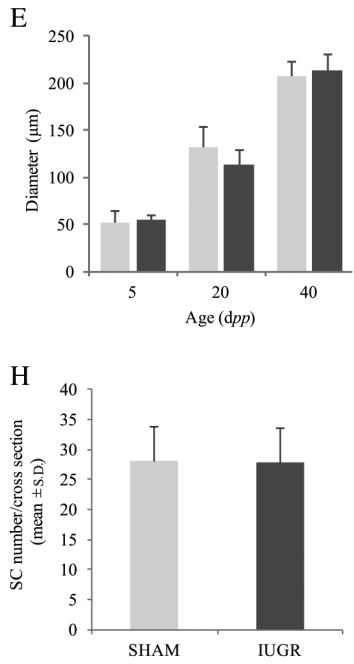
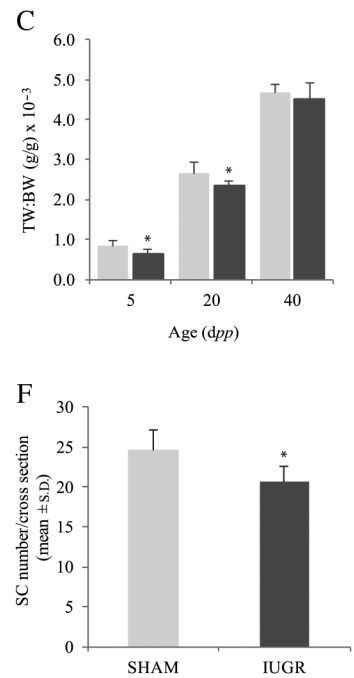

I

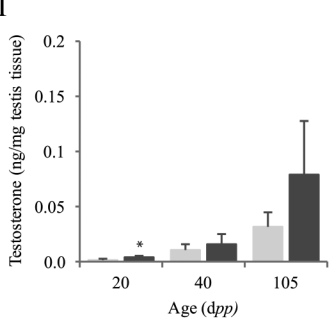

Figure 2

IUGR rats have reduced testis weight at 5 and 20 dpp. (A) Mean \pm s.D. of testis weight, (B) mean body weight and (C) mean testis weight to body weight ratio $\times 10^{-3}$ in IUGR and sham rats at 5, 20 and 40 dpp. (D) Gonocyte (G) and spermatogonia (SPG) counts in $5 \mathrm{dpp}$ rats were not different between IUGR and shams. Mean number \pm S.D. of G and SPG per tubule cross-section. (E) Tubule diameters were not different between IUGR and sham rats. Mean diameter \pm s.D. at 5, 20 and $40 \mathrm{dpp}$. Sertoli cell number was reduced in IUGR rats at $5 \mathrm{dpp}$. Mean number \pm S.D. of Sertoli cell per tubule cross section in (F) $5 \mathrm{dpp}$, (G) $20 \mathrm{dpp}$ and (H) $40 \mathrm{~d} p p$ old IUGR and sham animals. (I) Intratesticular testosterone was increased in IUGR rats at $20 \mathrm{dpp}$. Mean \pm s.D. of intratesticular testosterone concentrations at 20 and $40 \mathrm{dpp}$ rats ( $\mathrm{ng} / \mathrm{mg}$ testis tissue $\left.\times 10^{-3}\right)$. Asterisks denote a significant difference compared to shams; ${ }^{*} P<0.05,{ }^{*} P<0.001$.
The migration of gonocytes $(\mathrm{G})$ from the center of the seminiferous cords to the basement membrane is necessary for their differentiation into spermatogonia (SPG) and survival (Orth et al. 1997). To explore whether the postnatal migratory pathway of GC was altered by IUGR, we assessed the number of $G$ and SPG per seminiferous tubule cross-section in $5 \mathrm{~d} p p$ rats. GCs attached to the basement membrane of seminiferous tubules were considered SPG and GC in the tubule lumen were considered G. Moreover, SPG and G were distinguished based on their distinctive morphology, with gonocytes being large round cells with prominent nuclei, and spermatogonia being semicircular-shaped cells with the flattest edge attached to the basement membrane (Manku $\&$ Culty 2015). The number of seminiferous tubule crosssections ( $\mathrm{T}$ ) per image was also counted such that the number of cells per seminiferous tubular cross-section (G/T or SPG/T) could be calculated. Due to variation of tubules that could be counted, $24.4 \pm 9.8$ tubules/animal were analyzed in the IUGR group and $19.8 \pm 5.3$ tubules/ animal in the sham one. The mean number of G/T was not different between IUGR and sham rats at $5 \mathrm{~d} p p(0.89 \pm 0.3$ vs $0.86 \pm 0.1)$ as there was no difference in the mean number of SPG/T $(0.49 \pm 0.24$ vs $0.29 \pm 0.13)$ (Fig. 2D).
For the estimation of seminiferous tubule diameters, cross-sections of 20 seminiferous tubules per animal were randomly chosen and measured in each animal at 5, 20 and $40 \mathrm{~d} p p$. Three measurements of each cross-section of seminiferous tubules were made using Image software and the average between them was calculated.

IUGR rats did not exhibit a significant reduction in the diameter of seminiferous tubules compared to controls at any age (Fig. 2E).

For quantification of the SC population, WT1positive cells were counted in $38.0 \pm 5.40$ tubules/animal in the IUGR group and in $33.9 \pm 10.9$ tubules/animal in the sham group.

SC number was significantly lower in IUGR rats at 5 $\mathrm{d} p p$ compared to controls $(P<0.05)$ (Fig. $2 \mathrm{~F})$, whereas it was not significantly different between the two groups at 20 and $40 \mathrm{~d} p p$ (Fig. 2G and H).

\section{Intratesticular and serum hormonal measurements}

To investigate the influence of IUGR on LC function, intratesticular testosterone concentration (ITT) was measured at 20 and $40 \mathrm{~d} p p$. 
ITT was significantly increased in IUGR at $20 \mathrm{~d} p p$ compared to shams $(3.7 \pm 1.4$ vs $2.1 \pm 0.9 \mathrm{pg} / \mathrm{mg}$ of testis tissue, $P<0.05$ ), whereas it was not different at $40 \mathrm{~d} p p$, even though a tendency to increased levels in IUGR rats was noted (Fig. 2I and Supplementary Table 3).

Intratesticular estradiol levels at 20 and $40 \mathrm{~d} p p$ were assessed to verify the integrity of testicular aromatase activity after IUGR. No significant difference was found in the intraparenchymal estradiol concentrations at these ages (data not shown).

To assess whether the observed difference in ITT levels was dependent on hypothalamic-pituitary regulation, $\mathrm{LH}$ and FSH serum levels were measured at 20 and $40 \mathrm{~d} p p$. No significant differences in gonadotrophins serum levels were observed between IUGR and sham rats (Supplementary Table 3).

\section{Discussion}

Prenatal events causing modifications in the gonads can have long-term consequences on reproductive health and gamete integrity. In this regard, epidemiological studies have reported conflicting results on testicular function in IUGR individuals, whereas animal studies have shown that IUGR induced by maternal undernutrition can impair testicular structure, functionality and sperm parameters. Animal models manipulating uteroplacental blood flow to induce IUGR are more appropriate to investigate IUGR morbidity in relation to Western countries, where malnutrition is seldom the cause of IUGR. We used a UPI rat model to investigate the effects of IUGR on gene expression, structure and functionality in the postnatal testis.

\section{Cell metabolism}

Comparison of the gene expression profile between IUGR and shams showed changes in genes involved in the regulation of metabolic processes. Fetal hypoxia increased the expression of the mitochondrial enzymes $C s$ (the first enzyme in the citric acid cycle) and Hadh (an indicator of fatty acids $\beta$-oxidation) in $5 \mathrm{~d} p p$ rat testicular tissue, suggesting a modification of the metabolic balance within testicular cells to cope with the reduced supply from ligated uterine arteries.

Increased Slc2a1 (also known as Glut-1) expression (the main glucose transporter across the plasma membrane) was detected by Lane and coworkers in the liver of newborn IUGR rats and normalized after the neonatal period, suggesting a transient adaptive response to the limited blood provision during the fetal period (Lane et al. 1999).

Interestingly, we detected a modification of Glut-1 expression only in the testis of young adult rats (40 dpp). SCs sustain developing germ cells providing them with metabolic substrates. To do this, SCs internalize glucose from the interstitial space via GLUT-1 and GLUT-3 glucose transporters (Galardo et al. 2008) and use it to produce lactate via glycolysis pathway. Lactate produced from SCs is the main energy source for spermatogenic cells and a survival factor (Erkkila et al. 2002, Boussouar \& Benahmed 2004). Therefore, the upregulation of Glut-1 observed in peripubertal IUGR rats may be necessary to support germ cell metabolism at onset of spermatogenesis, when metabolic requirements rise considerably, suggesting that compensatory mechanisms can be modulated according to the testicular developmental stage. Most importantly, these findings open the hypothesis that a dysregulation of GLUT-1 determining a blunted glucose uptake from SCs could play a role in male idiopathic subfertility. This issue merits further investigation and if a role of GLUT-1 in male infertility should emerge, targeting GLUT-1 could open a therapeutic option for these patients.

\section{SC function and testis size}

Several genes selected for their functional role in SCs were dysregulated in response to UPI; at $5 \mathrm{~d} p p$, Sox 9 expression was decreased in IUGR rats compared to shams. Sox9 is a transcription factor of the SOX (SRY-related HMG box) family, which has a primary role in mammalian testis differentiation (Kanai et al. 2005). From testicular cord formation, Sox9 is selectively expressed in SCs and has therefore been proposed as a SC marker (Morais da Silva et al. 1996, Hemendinger et al. 2002). Accordingly, SC number was reduced at this age, suggesting that UPI can interfere with the attainment of an appropriate number of SCs at birth. However, among several SC-specific transcripts analyzed, only Sox9 was affected in IUGR animals at this age, indicating that the transcriptional response is not only a reflection of the reduced SC number. The functional consequences of these transcriptional changes remain to be studied.

In line with the finding of reduced SC number, the major determinant of gonadal size in the prepubertal age (Rey 2003), testis weight normalized to body weight was significantly lower in IUGR rats at 5 and $20 \mathrm{~d} p p$, indicating that IUGR affected gonadal weight to a greater extent than whole body weight. Genovese and coworkers reported

Published by Bioscientifica Ltd. 
a significant reduction of testis weight and SC number in adult rats whose growth was restricted both in utero and postnatally by reduction of the nutritional intake. However, the ratio of testis weights to body weights was increased, indicating that general body development was more severely affected than the testis development itself (Genovese et al. 2010).

Despite a reduction of seminiferous tubule diameter is expected to occur when SC number reduces, we did not observe such a difference. This discrepancy has been observed by others (Hazra et al. 2014) and remains to be explained. However, the magnitude of SC reduction in our study, although significant, was of $\sim 16 \%$ compared to controls, probably being not sufficient to produce a reduction in the tubular diameter.

To our knowledge, our report is the first demonstrating that IUGR can produce postnatal changes in the testis size, which appear to be mediated by a reduction in SC number.

Catch-up growth in both testis and body weight occurred by $20 \mathrm{~d} p p$, and testis weight normalized to body weight was comparable between groups at $40 \mathrm{~d} p p$.

In 20 and $40 \mathrm{~d} p p$ old rats, the gene changes detected in IUGR vs sham animals may be interpreted in the light of testis weight catch-up growth. In postnatal life, immature SCs proliferate until $16 \mathrm{~d} p p$ in the rat. After this period, intratesticular testosterone rise induces SC maturation and AMH production is downregulated (Sharpe et al. 2003). The increased Amh expression observed in $20 \mathrm{~d} p p$ IUGR animals suggests a delay in SC maturation that would allow a prolonged mitotic phase and the production of more SCs to repopulate the testis and ultimately restore testis size. In support of this hypothesis, Cdkn1a expression was downregulated in $20 \mathrm{~d} p p$ IUGR rats in comparison to shams. Cdkn1a is a cell cycle inhibitor that regulates adult SC number and whose knockout has been shown to produce an increase in SC number and in testis weight (Holsberger et al. 2005). Similarly, the expression of Fshr was increased in IUGR rats at 20 and $40 \mathrm{~d} p p$ compared to shams, suggesting an amplification of FSH signaling. FSH is the main factor that regulates SC function and allows an adequate SC proliferation (Petersen \& Soder 2006). Although the proliferation rate of SCs was not assessed in this study, these transcriptional changes in IUGR animals can hypothetically act in concert to restore SC number and ultimately testicular size.

Finally, in 40-d $p p$-old IUGR rats, we observed a downregulation of Kitl, encoding for the stem cell factor (SCF), produced exclusively by SCs and whose interaction with the receptor c-kit expressed in SPG is crucial for spermatogenesis (Petersen \& Soder 2006). Thus, implications of an altered SCF/c-kit signaling on GC development in the IUGR rat testis cannot be excluded.

\section{LC function}

Data from different animal species subjected to malnutrition during pregnancy have shown reduced serum testosterone levels in male offspring (Zambrano et al. 2005, Toledo et al. 2011). In contrast to the effects observed in malnutrition models, two studies focusing on renal effects of UPI in rats, coincidentally reported increased serum levels of testosterone in adult rats (Ojeda et al. 2007, Baserga et al. 2009). As serum testosterone levels exhibit circadian fluctuations, we measured intraparenchymal testosterone levels, a more reliable measure of testosterone production by the testis. In line with the aforementioned studies, we detected significantly increased intratesticular testosterone levels in $20 \mathrm{~d} p p$ IUGR rats compared to shams. At $40 \mathrm{~d} p p$, testosterone was 1.4-fold increased, compared to the control group, although it did not reach statistical significance. Serum gonadotrophins levels were not different between IUGR and sham rats at any age, indicating that the increased testosterone production was independent from pituitary regulation. Nevertheless, two markers of LC function, Cyp17 and Tspo were upregulated in $5 \mathrm{~d} p p$ IUGR rats compared to shams. As both enzymes are involved in androgen synthesis, these changes could be preliminary to the significant increase in ITT levels observed at $20 \mathrm{~d} p p$, when gene expression was, however, no longer different between the two groups.

The increased testosterone levels may be finalized at providing an equal amount of circulating testosterone despite the reduced testis size. Moreover, androgens indirectly mediate SC proliferation and maturation (Johnston et al. 2004) and have been shown to contribute to the restoration of testis weight in hypogonadal mice more substantially than FSH alone (Haywood et al. 2003). Thus, the increased intratesticular testosterone concentrations in IUGR rats may also contribute at normalizing SC number and allowing catch-up growth of testis size.

\section{IGF/insulin pathways}

IGF/insulin pathways have been shown to play an important role in testis, being involved in the regulation of

Published by Bioscientifica Ltd. 
both SC and LC function. Selective knockout of $I g f 1 r$ and Insr in mice SCs decreases the proliferation rate of immature SCs during the early postnatal period, ultimately affecting adult testis size and daily sperm output (Pitetti et al. 2013). Moreover, in vitro and in vivo studies in rodents demonstrated a determinant role of IGF-I in regulating survival and testosterone production by LC in postnatal life (Baker et al. 1996, Colon et al. 2007, Svechnikov et al. 2010). Our expression analysis revealed an upregulation of three different key components of the IGF/insulin pathway (Igf1r, Irs2 and Insr) in IUGR rats compared to shams at 5, 20 and $40 \mathrm{~d} p p$, respectively, suggesting a possible influence of this system both on SC number and testosterone production by LC during the catch-up growth phase occurring in IUGR rat testis from $20 \mathrm{~d} p p$.

\section{Conclusion}

Collectively, these results provide evidence that IUGR induced by UPI interfere with testis development, as indicated by testicular size impairment and reduced SC number in neonatal rats. The recovery of testicular weight observed by three weeks of age appears to be regulated at multiple levels, by a fine and complex interplay between genes involved in SC function, steroidogenesis and cellular homeostasis, which ultimately produce a restoration of the organ size. Further studies are needed to corroborate these findings and to verify whether the resumption of SC number and testis weight reflects an intact organ function in terms of reproductive performance and gamete integrity.

Moreover, perturbation of SC development has been proposed as a player in the pathogenesis of the testicular dysgenesis syndrome, a complex of different diseases (including low sperm count and increased risk of testicular cancer) that may share the same causal mechanisms and has been tightly related to IUGR in epidemiological studies. The IUGR-induced alterations in gene expression profile of SCs observed in our study could represent a link between these conditions and need to be taken into account to orientate future investigations.

Although preliminary, our study sheds light on previously unknown consequences of an event commonly affecting human gestations. For the obvious reason of limited access to human tissues, genetic arrangement and morphology of the human testis after IUGR is largely unknown. This work could serve as reference to orientate future studies and translate these observations into human pathology.

\section{Supplementary data}

This is linked to the online version of the paper at http://dx.doi.org/10.1530/ JOE-16-0418.

\section{Declaration of interest}

The authors declare that there is no conflict of interest that could be perceived as prejudicing the impartiality of the research reported.

\section{Funding}

This study was supported by research grants from the Swedish Research Council, Children's Cancer Found, Stockholm County Council Research Funds, the Frimurare Foundation and Karolinska Institutet. Valentina Pampanini received grant support from the Sällskapet Barnavård foundation.

Acknowledgements

The authors are grateful to Dr Luise Landreh for her contribution in performing TaqMan Low-Density Arrays.

\section{References}

Arends NJ, Boonstra VH, Duivenvoorden HJ, Hofman PL, Cutfield WS \& Hokken-Koelega AC 2005 Reduced insulin sensitivity and the presence of cardiovascular risk factors in short prepubertal children born small for gestational age (SGA). Clinical Endocrinology 62 44-50. (doi:10.1111/j.1365-2265.2004.02171.x)

Baker J, Hardy MP, Zhou J, Bondy C, Lupu F, Bellve AR \& Efstratiadis A 1996 Effects of an Igf1 gene null mutation on mouse reproduction. Molecular Endocrinology 10 903-918. (doi:10.1210/me.10.7.903)

Barker DJ 1990 The fetal and infant origins of adult disease. British Medical Journal 301 1111. (doi:10.1136/bmj.301.6761.1111)

Barker DJ 1995 Fetal origins of coronary heart disease. British Medical Journal 311 171-174. (doi:10.1136/bmj.311.6998.171)

Barker DJ, Bull AR, Osmond C \& Simmonds SJ 1990 Fetal and placental size and risk of hypertension in adult life. British Medical Journal $\mathbf{3 0 1}$ 259-262. (doi:10.1136/bmj.301.6746.259)

Barker DJ, Martyn CN, Osmond C, Hales CN \& Fall CH 1993 Growth in utero and serum cholesterol concentrations in adult life. British Medical Journal 307 1524-1527. (doi:10.1136/bmj.307.6918.1524)

Baserga M, Bares AL, Hale MA, Callaway CW, McKnight RA, Lane PH \& Lane RH 2009 Uteroplacental insufficiency affects kidney VEGF expression in a model of IUGR with compensatory glomerular hypertrophy and hypertension. Early Human Development $\mathbf{8 5}$ 361-367. (doi:10.1016/j.earlhumdev.2008.12.015)

Boussouar F \& Benahmed M 2004 Lactate and energy metabolism in male germ cells. Trends in Endocrinology and Metabolism 15 345-350. (doi:10.1016/j.tem.2004.07.003)

Colon E, Zaman F, Axelson M, Larsson O, Carlsson-Skwirut C, Svechnikov KV \& Soder O 2007 Insulin-like growth factor-I is an important antiapoptotic factor for rat leydig cells during postnatal development. Endocrinology 148 128-139. (doi:10.1210/ en.2006-0835)

Dupont C, Cordier AG, Junien C, Mandon-Pepin B, Levy R \& Chavatte-Palmer P 2012 Maternal environment and the reproductive function of the offspring. Theriogenology 78 1405-1414. (doi:10.1016/j.theriogenology.2012.06.016)

Engelbregt MJ, Houdijk ME, Popp-Snijders C \& Delemarre-van de Waal HA 2000 The effects of intra-uterine growth retardation and postnatal undernutrition on onset of puberty in male and female rats. Pediatric Research 48 803-807. (doi:10.1203/00006450-200012000-00017) 
Engelbregt MJ, van Weissenbruch MM, Popp-Snijders C \& Delemarre-van de Waal HA 2002 Delayed first cycle in intrauterine growth-retarded and postnatally undernourished female rats: follicular growth and ovulation after stimulation with pregnant mare serum gonadotropin at first cycle. Journal of Endocrinology 173 297-304. (doi:10.1677/joe.0.1730297)

Erkkila K, Aito H, Aalto K, Pentikainen V \& Dunkel L 2002 Lactate inhibits germ cell apoptosis in the human testis. Molecular Human Reproduction 8 109-117. (doi:10.1093/molehr/8.2.109)

Forsen T, Eriksson JG, Tuomilehto J, Osmond C \& Barker DJ 1999 Growth in utero and during childhood among women who develop coronary heart disease: longitudinal study. British Medical Journal 319 1403-1407. (doi:10.1136/bmj.319.7222.1403)

Gagnon R 2003 Placental insufficiency and its consequences. European Journal of Obstetrics and Gynecology and Reproductive Biology 110 (Supplement 1) S99-S107. (doi:10.1016/S0301-2115(03)00179-9)

Galardo MN, Riera MF, Pellizzari EH, Chemes HE, Venara MC, Cigorraga SB \& Meroni SB 2008 Regulation of expression of Sertoli cell glucose transporters 1 and 3 by FSH, IL1 beta, and bFGF at two different time-points in pubertal development. Cell and Tissue Research 334 295-304. (doi:10.1007/s00441-008-0656-y)

Genovese P, Nunez ME, Pombo C \& Bielli A 2010 Undernutrition during foetal and post-natal life affects testicular structure and reduces the number of Sertoli cells in the adult rat. Reproduction in Domestic Animals 45 233-236. (doi:10.1111/j.1439-0531.2008.01244.x)

Gnessi L, Fabbri A \& Spera G 1997 Gonadal peptides as mediators of development and functional control of the testis: an integrated system with hormones and local environment. Endocrine Reviews 18 541-609. (doi:10.1210/er.18.4.541)

Hales CN \& Barker DJ 2001 The thrifty phenotype hypothesis. British Medical Bulletin 60 5-20. (doi:10.1093/bmb/60.1.5)

Hales CN, Barker DJ, Clark PM, Cox LJ, Fall C, Osmond C \& Winter PD 1991 Fetal and infant growth and impaired glucose tolerance at age 64. British Medical Journal 303 1019-1022. (doi:10.1136/ bmj.303.6809.1019)

Haywood M, Spaliviero J, Jimemez M, King NJ, Handelsman DJ \& Allan CM 2003 Sertoli and germ cell development in hypogonadal (hpg) mice expressing transgenic follicle-stimulating hormone alone or in combination with testosterone. Endocrinology 144 509-517. (doi:10.1210/en.2002-220710)

Hazra R, Upton D, Jimenez M, Desai R, Handelsman DJ \& Allan CM 2014 In vivo actions of the Sertoli cell glucocorticoid receptor. Endocrinology 155 1120-1130. (doi:10.1210/en.2013-1940)

Hemendinger RA, Gores P, Blacksten L, Harley V \& Halberstadt C 2002 Identification of a specific Sertoli cell marker, Sox9, for use in transplantation. Cell Transplantation 11 499-505.

Hernandez MI \& Mericq V 2008 Impact of being born small for gestational age on onset and progression of puberty. Best Practice and Research Clinical Endocrinology and Metabolism 22 463-476. (doi:10.1016/j.beem.2008.02.003)

Hokken-Koelega AC 2002 Timing of puberty and fetal growth. Best Practice and Research Clinical Endocrinology and Metabolism 16 65-71. (doi:10.1053/beem.2002.0181)

Holsberger DR, Buchold GM, Leal MC, Kiesewetter SE, O’Brien DA, Hess RA, Franca LR, Kiyokawa H \& Cooke PS 2005 Cell-cycle inhibitors p27Kip1 and p21Cip1 regulate murine Sertoli cell proliferation. Biology of Reproduction 72 1429-1436. (doi:10.1095/ biolreprod.105.040386)

Jensen RB, Vielwerth S, Larsen T, Greisen G, Veldhuis J \& Juul A 2007 Pituitary-gonadal function in adolescent males born appropriate or small for gestational age with or without intrauterine growth restriction. Journal of Clinical Endocrinology and Metabolism 92 1353-1357. (doi:10.1210/jc.2006-2348)

Johnston H, Baker PJ, Abel M, Charlton HM, Jackson G, Fleming L, Kumar TR \& O'Shaughnessy PJ 2004 Regulation of Sertoli cell number and activity by follicle-stimulating hormone and androgen during postnatal development in the mouse. Endocrinology 145 318-329. (doi:10.1210/en.2003-1055)

Kanai Y, Hiramatsu R, Matoba S \& Kidokoro T 2005 From SRY to SOX9: mammalian testis differentiation. Journal of Biochemistry 138 13-19. (doi:10.1093/jb/mvi098)

Kotsampasi B, Balaskas C, Papadomichelakis G \& Chadio SE 2009 Reduced Sertoli cell number and altered pituitary responsiveness in male lambs undernourished in utero. Animal Reproduction Science 114 135-147. (doi:10.1016/j.anireprosci.2008.08.017)

Lane RH, Crawford SE, Flozak AS \& Simmons RA 1999 Localization and quantification of glucose transporters in liver of growth-retarded fetal and neonatal rats. American Journal of Physiology 276 E135-E142.

Law CM, Barker DJ, Osmond C, Fall CH \& Simmonds SJ 1992 Early growth and abdominal fatness in adult life. Journal of Epidemiology and Community Health 46 184-186. (doi:10.1136/jech.46.3.184)

Main KM, Jensen RB, Asklund C, Hoi-Hansen CE \& Skakkebaek NE 2006 Low birth weight and male reproductive function. Hormone Research 65 (Supplement 3) 116-122. (doi:10.1159/000091516)

Manku G \& Culty M 2015 Mammalian gonocyte and spermatogonia differentiation: recent advances and remaining challenges. Reproduction 149 R139-R157. (doi:10.1530/REP-14-0431)

Morais da Silva S, Hacker A, Harley V, Goodfellow P, Swain A \& Lovell-Badge R 1996 Sox9 expression during gonadal development implies a conserved role for the gene in testis differentiation in mammals and birds. Nature Genetics 14 62-68. (doi:10.1038/ng0996-62)

Ojeda NB, Grigore D, Yanes LL, Iliescu R, Robertson EB, Zhang H \& Alexander BT 2007 Testosterone contributes to marked elevations in mean arterial pressure in adult male intrauterine growth restricted offspring. American Journal of Physiology: Regulatory, Integrative and Comparative Physiology 292 R758-R763. (doi:10.1152/ ajpregu.00311.2006)

Orth JM, Qiu J, Jester WF Jr \& Pilder S 1997 Expression of the c-kit gene is critical for migration of neonatal rat gonocytes in vitro. Biology of Reproduction 57 676-683. (doi:10.1095/biolreprod57.3.676)

Persson I, Ahlsson F, Ewald U, Tuvemo T, Qingyuan M, von Rosen D \& Proos L 1999 Influence of perinatal factors on the onset of puberty in boys and girls: implications for interpretation of link with risk of long term diseases. American Journal of Epidemiology 150 747-755. (doi:10.1093/oxfordjournals.aje.a010077)

Petersen C \& Soder O 2006 The sertoli cell - a hormonal target and 'super' nurse for germ cells that determines testicular size. Hormone Research 66 153-161. (doi:10.1159/000094142)

Peterside IE, Selak MA \& Simmons RA 2003 Impaired oxidative phosphorylation in hepatic mitochondria in growth-retarded rats. American Journal of Physiology: Endocrinology and Metabolism 285 E1258-E1266. (doi:10.1152/ajpendo.00437.2002)

Pitetti JL, Calvel P, Zimmermann C, Conne B, Papaioannou MD, Aubry F, Cederroth CR, Urner F, Fumel B, Crausaz M, et al. 2013 An essential role for insulin and IGF1 receptors in regulating sertoli cell proliferation, testis size, and FSH action in mice. Molecular Endocrinology 27 814-827. (doi:10.1210/me.2012-1258)

Puglianiello A, Germani D, Antignani S, Tomba GS \& Cianfarani S 2007 Changes in the expression of hypothalamic lipid sensing genes in rat model of intrauterine growth retardation (IUGR). Pediatric Research 61 433-437. (doi:10.1203/pdr.0b013e3180332d4e)

Rae MT, Rhind SM, Fowler PA, Miller DW, Kyle CE \& Brooks AN 2002 Effect of maternal undernutrition on fetal testicular steroidogenesis during the CNS androgen-responsive period in male sheep fetuses. Reproduction 124 33-39. (doi:10.1530/rep.0.1240033)

Rey R 2003 Regulation of spermatogenesis. Endocrine Development 5 38-55. (doi:10.1159/000069300)

Selak MA, Storey BT, Peterside I \& Simmons RA 2003 Impaired oxidative phosphorylation in skeletal muscle of intrauterine growth-retarded rats. American Journal of Physiology: Endocrinology and Metabolism $\mathbf{2 8 5}$ E130-E137. (doi:10.1152/ajpendo.00322.2002) http://joe.endocrinology-journals.org

DOI: $10.1530 / \mathrm{JOE}-16-0418$
(C) 2017 The authors Printed in Great Britain
Published by Bioscientifica Ltd 
Sharpe RM, McKinnell C, Kivlin C \& Fisher JS 2003 Proliferation and functional maturation of Sertoli cells, and their relevance to disorders of testis function in adulthood. Reproduction 125 769-784. (doi:10.1530/rep.0.1250769)

Silveira PP, Portella AK, Goldani MZ \& Barbieri MA 2007 Developmental origins of health and disease (DOHaD). Jornal de Pediatria 83 494-504. (doi:10.2223/jped.1728)

Skakkebaek NE, Rajpert-De Meyts E \& Main KM 2001 Testicular dysgenesis syndrome: an increasingly common developmental disorder with environmental aspects. Human Reproduction 16 972-978. (doi:10.1093/humrep/16.5.972)

Sofikitis N, Giotitsas N, Tsounapi P, Baltogiannis D, Giannakis D \& Pardalidis N 2008 Hormonal regulation of spermatogenesis and spermiogenesis. Journal of Steroid Biochemistry and Molecular Biology 109 323-330. (doi:10.1016/j.jsbmb.2008.03.004)

Svechnikov K, Landreh L, Weisser J, Izzo G, Colon E, Svechnikova I \& Soder O 2010 Origin, development and regulation of human Leydig cells. Hormone Research in Paediatrics 73 93-101. (doi:10.1159/000277141)

Thompson LP \& Al-Hasan Y 2012 Impact of oxidative stress in fetal programming. Journal of Pregnancy 2012582748. (doi:10.1155/2012/582748)

Toledo FC, Perobelli JE, Pedrosa FP, Anselmo-Franci JA \& Kempinas WD 2011 In utero protein restriction causes growth delay and alters sperm parameters in adult male rats. Reproductive Biology and Endocrinology 9 94. (doi:10.1186/1477-7827-9-94)
Tsirka AE, Gruetzmacher EM, Kelley DE, Ritov VH, Devaskar SU \& Lane RH 2001 Myocardial gene expression of glucose transporter 1 and glucose transporter 4 in response to uteroplacental insufficiency in the rat. Journal of Endocrinology 169 373-380. (doi:10.1677/ joe.0.1690373)

Veening MA, van Weissenbruch MM, Roord JJ \& de Delemarre-van Waal HA 2004 Pubertal development in children born small for gestational age. Journal of Pediatric Endocrinology and Metabolism 17 1497-1505. (doi:10.1515/jpem.2004.17.11.1497)

Vuguin PM 2007 Animal models for small for gestational age and fetal programming of adult disease. Hormone Research 68 113-123. (doi:10.1159/000100545)

Vuguin P, Raab E, Liu B, Barzilai N \& Simmons R 2004 Hepatic insulin resistance precedes the development of diabetes in a model of intrauterine growth retardation. Diabetes 53 2617-2622. (doi:10.2337/diabetes.53.10.2617)

Wigglesworth JS 1964 Experimental growth retardation in the foetal rat. Journal of Pathology and Bacteriology 88 1-13.

Zambrano E, Rodriguez-Gonzalez GL, Guzman C, Garcia-Becerra R, Boeck L, Diaz L, Menjivar M, Larrea F \& Nathanielsz PW 2005 A maternal low protein diet during pregnancy and lactation in the rat impairs male reproductive development. Journal of Physiology 563 275-284. (doi:10.1113/jphysiol.2004.078543)

Zambrano E, Guzman C, Rodriguez-Gonzalez GL, Durand-Carbajal M \& Nathanielsz PW 2014 Fetal programming of sexual development and reproductive function. Molecular and Cellular Endocrinology $\mathbf{3 8 2}$ 538-549. (doi:10.1016/j.mce.2013.09.008)

Received in final form 28 October 2016

Accepted 24 November 2016

Accepted Preprint published online 24 November 2016 (c) 2017 The authors Printed in Great Britain
Published by Bioscientifica Ltd. 